\title{
Key changes to improve social presence of a virtual health assistant promoting colorectal cancer screening informed by a technology acceptance model
}

Melissa J. Vilaro ${ }^{1 *}$, Danyell S. Wilson-Howard², Mohan S. Zalake ${ }^{3}$, Fatemeh Tavassoli ${ }^{3}$, Benjamin C. Lok ${ }^{3}$, François P. Modave ${ }^{4}$, Thomas J. George ${ }^{5}$, Folakemi Odedina ${ }^{6}$, Peter J. Carek ${ }^{7}$ and Janice L. Krieger ${ }^{1}$

\begin{abstract}
Background: Understanding how older, minoritized patients attend to cues when interacting with web-based health messages may provide opportunities to improve engagement with novel health technologies. We assess acceptance-promoting and acceptance-inhibiting cues of a web-based, intervention promoting colorectal cancer (CRC) screening with a home stool test among Black women.

Materials and methods: Focus group and individual interview data informed iterative changes to a race- and gender-concordant virtual health assistant (VHA). A user-centered design approach was used across 3 iterations to identify changes needed to activate cues described as important; such as portraying authority and expertise. Questionnaire data were analyzed using non-parametric tests for perceptions of cues. Analysis was guided by the Technology Acceptance Model.

Results: Perceptions of interactivity, social presence, expertise, and trust were important cues in a VHA-delivered intervention promoting CRC screening. Features of the web-based platform related to ease of navigation and use were also discussed. Participant comments varied across the 3 iterations and indicated acceptance of or a desire to improve source cues for subsequent iterations. We highlight the specific key changes made at each of three iterative versions of the interactive intervention in conjunction with user perception of changes.

Discussion: Virtual agents can be adapted to better meet patient expectations such as being a trustworthy and expert source. Across three evolving versions of a Black, VHA, cues for social presence were particularly important. Social presence cues helped patients engage with CRC screening messages delivered in this novel digital context.

Conclusions: When using a VHA to disseminate health information, cues associated with acceptability can be leveraged and adapted as needed for diverse audiences. Patient characteristics (age, identity, health status) are important to note as they may affect perceptions of a novel health technologies ease of use and relevancy according to the leading models.
\end{abstract}

\footnotetext{
*Correspondence: mgraveley@ufl.edu

1 STEM Translational Communication Center (STCC), University of Florida,

Weimer Hall 2043, PO Box 118400, Gainesville, FL 32611, USA

Full list of author information is available at the end of the article
} original author(s) and the source, provide a link to the Creative Commons licence, and indicate if changes were made. The images or other third party material in this article are included in the article's Creative Commons licence, unless indicated otherwise in a credit line to the material. If material is not included in the article's Creative Commons licence and your intended use is not permitted by statutory regulation or exceeds the permitted use, you will need to obtain permission directly from the copyright holder. To view a copy of this licence, visit http://creativecommons.org/licenses/by/4.0/. The Creative Commons Public Domain Dedication waiver (http://creativeco mmons.org/publicdomain/zero/1.0/) applies to the data made available in this article, unless otherwise stated in a credit line to the data. 
Keywords: Technology acceptance model, Colorectal cancer screening, Web-based intervention, Virtual agent, Rural health

\section{Introduction}

Technology, cancer screening, and an aging population

With the ongoing expansion of telemedicine for use among rural and aging populations [1, 2], contextualizing facilitators and barriers of health technology use and non-use is needed. Despite this need, systematic exploration of features predicting acceptance and use of health technologies among aging, rural, and minoritized populations is lacking [3-5]. The Technology Acceptance Model (TAM) is a framework for establishing acceptability and usability of technology [6]. TAM relies on two constructs; perceived usefulness (e.g., can the technology enhance my performance) and perceived ease of use (e.g., will using the technology be low effort). An adapted version, the Senior Technology Acceptance Model (STAM) incorporates the role of individual characteristics which can include health conditions, cognitive ability, or physical functioning to determine how older adults use technology for health [7]. These frameworks are considered the most relevant to exploring patient perceptions of health technologies among computer scientists developing health applications [8].

Technology may play an important role in enhancing access to colorectal cancer (CRC) screening for at risk adults. CRC is the 3rd leading cause of cancer deaths among US adults [9]. Although all adults at average risk of CRC should begin regular screening at age 50, screening disparities exist. Historically, Black adults have lower CRC screening rates compared to White adults. Despite declines in Black-White disparities in late-stage diagnosis, incidence in CRC remains higher among Black adults [10]. In addition to race, there are significant geographic inequalities. Rural adults are also less likely to obtain screening within guidelines compared to urban counterparts $[11,12]$. The Fecal Immunochemical Test (FIT) is a non-invasive, low-cost, acceptable, accurate screening modality for adults at average risk and may help improve screening rates if offered over colonoscopy [13]. As the FIT can be completed at home and mailed to a lab for processing, it has potential to enhance access to and ease of screening.

\section{Virtual human agents as a source of acceptable cancer communication}

Innovations that supplement and support patient care may be an important tool for improving communication and access to needed cancer screenings. One emerging tool is the use of virtual agents, which are customizable characters that allow for interactive dissemination of health communication. Virtual agents may facilitate informed decision-making, enhance trustworthiness, and improve patient engagement with health $[14,15]$.

It is well documented that a healthcare provider recommendation is a strong predictor of compliance with CRC screening [16-18]. Thus, if deemed a credible source, virtual health assistants (VHAs) may become a scalable, effective strategy to communicate cancer screening messages. Furthermore, VHAs may simultaneously support other public health goals. One objective of the Healthy People 2030's Health Communication and Health Information Technology Workgroup is to decrease the proportion of adults who report poor communication with their health care provider [19].

\section{Social presence}

Social presence, the general sense of being with another person, is important when using VHAs to communicate with patients [20]. Through the lens of TAM, social presence is relevant to patients accepting VHAs in part because perceptions of social presence can lead to a desire for future interaction [21]. Patients may perceive a virtual agent in a number of ways including warm [22], interested, friendly, or emotional about a conversation [23]. In previous work, cues associated with social presence promote a sense of acceptability and improved message engagement $[24,25]$.

The purpose of this paper is to describe specific design features (e.g., cues) adapted to improve acceptability and useability of a web-based intervention promoting CRC screening. The intervention is delivered by a race-and gender-concordant VHA and covers all screening modalities with a focus on FIT. This paper builds on previous work related to this project describing a user-centered design (UCD) process and analysis of cues [26-28]. Exploratory triangulation of qualitative and quantitative data contextualizes the impact of changes. We answer the following questions:

(1) What acceptance-promoting and acceptance-inhibiting cues are identified in a VHA-delivered intervention promoting $\mathrm{CRC}$ screening?

(2) What key changes improved patient perceptions of the intervention? 


\section{Methods}

\section{Study overview}

A convenience sample of non-Hispanic, Black women from a largely rural region of the southern U.S. participated in focus groups and individual think-aloud interviews between January 2017 and November 2018. Participants were recruited via flyers and community engagement as part of a larger study. Eligible participants were between 50 and 73 years old and proficient in English. Trained moderators facilitated a semi-structured discussion that was audio-recorded and transcribed. Participants also reported perceptions of the intervention, attitudes, behaviors, and demographic characteristics on paper questionnaires. Trained research assistants later entered questionnaire data into Qualtrics ${ }^{\mathrm{TM}}$ [29].

Participants viewed print prototypes (e.g., focus groups 1 and 2) or tested one of three iterations of the intervention on mobile Samsung Galaxy phones with headphones. Participants then discussed their perceptions of the prototypes and last filled out a paper questionnaire. Based on approved procedures from institutional review boards, prior to participation all individuals provided written informed consent. Participants received a $\$ 35$ gift card. All procedures were approved by Institutional Review Board, IRB201601642. All methods were carried out in accordance with relevant guidelines and regulations.

\section{Data analysis}

For qualitative data, we conducted thematic analysis of patient comments using comparative analysis across all versions tested (print prototypes, interactive version 1 , interactive version 2 , and interactive version 3 ) (Table 1 ). Interactive versions included verbal information provided by the virtual health assistant, closed-ended questions, and nonverbal behaviors with animated motion. Trained raters coded transcripts and attained acceptable inter-rater reliability, described elsewhere in a paper that describes participant reactions to screening and the VHA [27]. The focus of this paper is to detail how participant comments were used to inform and alter specific development aspects of the VHA across successive iterations. Team members discussed and tracked when changes were made to the VHA and intervention. This process allowed for a detailed cataloging of the specific key adaptations made throughout the UCD process [30].

While qualitative data was the primary driver of the iterative changes throughout the design and evaluation process, we conducted post-design analysis of the quantitative data collected via paper questionnaires. This post-design analysis served two goals; one to assess if questionnaire data was consistent with the insights
Table 1 Participant characteristics and group type

\begin{tabular}{llll}
\hline Group type & Stimuli & N & Age (mean, SD) \\
\hline Focus groups & & & \\
1 & Print prototypes & 5 & $64.2(3.4)$ \\
2 & Print prototypes & 8 & $60.8(6.9)$ \\
3 & Interactive version 1 & 7 & $55.8(5.0)$ \\
4 & Interactive version 1 & 4 & $55.7(7.2)$ \\
5 & Interactive version 2 & 7 & $60.0(2.0)$ \\
6 & Interactive version 2 & 1 & 60 \\
7 & Interactive version 3 & 11 & $62.1(6.3)$ \\
8 & Interactive version 3 & 4 & $59.7(5.5)$ \\
Think-aloud interviews & & \\
$1-6$ & Interactive version 3 & 6 & $63.5(3.4)$ \\
Total & & 53 & $60.9(5.5)$ \\
\hline
\end{tabular}

Focus groups \#4 and \#6 each had one non-black participant, not represented in total N. Groups \#2, \#3, and \#5 are each missing one response for age from the questionnaire data

derived from qualitative data and two to provide additional insights regarding when discernable improvements may have been perceived, across the three interactive versions. While all participant comments informed the intervention, only participants who tested interactive prototypes (i.e., version 1, 2, and 3) are included in exploratory statistical analysis of perceptions. Participant responses to questionnaire items were grouped in accordance with the version tested to facilitate comparisons across the three interactive versions. Overall, descriptive statistics were computed, independent-samples Kruskal-Wallis non-parametric tests were conducted on participant characteristics.

Perceptions of the VHA and the web-based app were analyzed to assess distributions of scores on questionnaire items adapted from validated measures. Responses reported on a Likert Scale $(1=$ strongly agree to $5=$ strongly disagree) were analyzed with the independent-samples nonparametric median tests as exploratory triangulation of qualitative data. One item was selected for each qualitatively derived cue. Statistical significance was set at $\leq 0.05$ after adjusting for multiple comparisons. When a significant main effect was found, post-hoc pairwise comparisons were conducted, also adjusted for multiple tests. Analysis was conducted using IBM SPSS Statistics $^{\mathrm{TM}}[31]$.

\section{Results}

Fifty-three non-Hispanic, Black women participated (Table 2). Marital status was similar across groups, however, participants who tested version 1 reported higher levels of education and income than those who tested version $3, p<0.05$. 
Table 2 Participant characteristics

\begin{tabular}{|c|c|}
\hline Age (mean, standard deviation) & $60.9(5.5)$ \\
\hline Race & $(\mathrm{N}, \%)$ \\
\hline Black/African American & $53(100 \%)$ \\
\hline \multicolumn{2}{|l|}{ Gender } \\
\hline Female & $53(100 \%)$ \\
\hline \multicolumn{2}{|l|}{ Marital status } \\
\hline Married & $13(24.5 \%)$ \\
\hline Divorced/separated & $15(28.3 \%)$ \\
\hline Single & $19(35.8 \%)$ \\
\hline Widowed & $6(11.3 \%)$ \\
\hline \multicolumn{2}{|l|}{ Employment } \\
\hline Full-time or part-time for pay & $18(34 \%)$ \\
\hline Retired & $17(32 \%)$ \\
\hline Unable to work due to disability & $9(17 \%)$ \\
\hline Unemployed & $6(11.3 \%)$ \\
\hline Volunteer or prefer not to answer & $3(5.6 \%)$ \\
\hline \multicolumn{2}{|l|}{ Income (2016) } \\
\hline$<\$ 20,000$ & $19(35.8 \%)$ \\
\hline$\$ 20,000-\$ 74,999$ & $13(24.5 \%)$ \\
\hline$\geq \$ 75,000$ & $2(4 \%)$ \\
\hline Prefer not to answer & $19(35.8 \%)$ \\
\hline \multicolumn{2}{|l|}{ Education } \\
\hline$\leq$ High school/GED/trade school & $28(52.7 \%)$ \\
\hline Some college or college grad & $19(35.8 \%)$ \\
\hline Postgraduate training & $3(5.6 \%)$ \\
\hline Prefer not to answer & $3(5.6 \%)$ \\
\hline Total participants & $53(100 \%)$ \\
\hline
\end{tabular}

\section{Qualitative results: perceptions of source cues and navigability}

Table 3 details specific key changes, and when they were made throughout the development process. Key changes addressed various cues within the domains of social presence, trust, expertise, and navigability, which overall are likely to influence acceptance and ease of use which are key components of TAM.

\section{Key changes to improve social presence}

Social presence improved with modifications to cues related to perceptions of the VHAs (1) movement, (2) being real versus fake, (3) being scary, and (4) ability to provide an interactive experience. Comments indicated that changes improved perceptions of these cues across versions. For example, when social presence was low participants said things like “...computers don't always understand, or they'll only have the information that was inputted to them, therefore, it's not like a thinking person. I'd almost prefer a person that could think and analyze things, and dissect it." (P103, FG2, print). Looking away from the VHA was an indicator of low social presence, “...I got where I quit looking at her doing it," (P113, FG5, VER2) and "...I just looked at that little thing... [laughter], after that I didn't look." (P46, FG4, VER1). When social presence was high participants said things like, "It's like she was talkin' to a live person when she's talkin' to us..." (P136, FG7, VER3). Motion capture was one technique used to improve perceptions of movement (Fig. 1).

Another cue strongly related to social presence were perceptions of the VHA being real or fake. By version 2, comments started to reflect a mix of participants thinking the VHA was real "for the most part she looked real" (P118, FG5, VER2) and questioning her realness "Why wasn't it a real person, real doctor?" (P114, FG5, VER2). By version 3, the VHA is described almost exclusively as real, "she did a beautiful job. One time, I couldn't even think that she wasn't a real person because of her wisdom that was comin' from her and from the test, and it did a very good job on that." (P132, FG8, VER3).

\section{App development to enhance trustworthiness}

Trust included cues related to the VHA's voice, friendliness, and appearance. While some participants testing early versions were reluctant to interact with the VHA, others indicated they would trust the VHA even though they don't typically trust doctors. This trust was due to the perception that the VHA, as a computer, had additional access to information which could be relayed without bias. With adaptations, aspects of trust were communicated when participants indicated they appreciated not feeling like a targeted population by the VHA. Comments included; "She didn't discriminate. Some people wound up doin' those things. They say, "Well, are you through the age between da, da, da? Are you Black? Are you Hispanic?" That was never..." (P137, FG7, VER3). Allowing women to feel communicated with versus targeted because of personal characteristics that are also non-modifiable risk factors, was an important cue; "I liked it because she didn't put no color in there, no age, none of that. What she was sayin', she was sayin' everybody" (P138, FG7, VER3). Another participant commented, "At one time, I thought I was bein' singled out, but no, this is goin' on with people all over the world" (P135, FG8, VER3).

\section{Expertise}

The VHA being perceived as a medical authority, attire, and age of the VHA influenced perceptions of expertise. Women liked that she looked professional in medical attire, "That's a professional without a suit." (P101, FG2, VER1). Changes such as adding a name badge, updating clothing to include a white medical coat, and adjusting 
Table 3 Key changes to acceptance-inhibiting cues to promote perceptions of VHA acceptability

\begin{tabular}{|c|c|c|c|}
\hline Cue & Key themes & Key changes & Version \\
\hline Clothing & Not professional (e.g., scrubs) & $\begin{array}{l}\text { Updated the VHA so she was dressed in business casual } \\
\text { clothing rather than scrubs }\end{array}$ & Print to $\vee 1$ \\
\hline Real/Fake & Low quality, animated, robotic looking & Changed lighting to introduce depth in visual features & V.1 to $V .2$ \\
\hline Scary/Creepy & Looked like a vampire (e.g., "fangs") & Added shading to mouth and teeth & V.1 to $V .2$ \\
\hline Expertise & Preference for doctor vs. nurse or lay health worker & Added white coat (e.g., business casual was too casual) & V.1 to $\vee .2$ \\
\hline Authority & $\begin{array}{l}\text { Preference for middle age (e.g., too young = not enough } \\
\text { knowledge vs. too old= not enough current knowl- } \\
\text { edge) }\end{array}$ & Removed gray hair & V.1 to $\vee .2$ \\
\hline Trustworthiness & $\begin{array}{l}\text { Desire for accurate, relevant information, desire to not } \\
\text { feel targeted }\end{array}$ & $\begin{array}{l}\text { Removed color-coded response options (e.g. red="no") } \\
\text { to prevent perception of judgment when answering } \\
\text { questions }\end{array}$ & V.1 to $V .2$ \\
\hline Navigability & $\begin{array}{l}\text { Perceptions of how easy it is to use and navigate through } \\
\text { the app }\end{array}$ & $\begin{array}{l}\text { Added pause button with ability to tap to pause. } \\
\text { Updated text size of subtitles. Removed user transition } \\
\text { from waiting room to clinic room }\end{array}$ & V.1 to $V .2$ \\
\hline Movement & $\begin{array}{l}\text { Unnatural movements, excessive hand gestures and } \\
\text { rocking }\end{array}$ & $\begin{array}{l}\text { Used motion capture suits to update motion to cor- } \\
\text { respond with script (e.g. breathing animation) }\end{array}$ & V.2 to V.3 \\
\hline Appearance & More feminine, more dignified & Changed hairstyle, added jewelry & V.2 to $V .3$ \\
\hline Friendliness/likability & Angry looking, stressed out, not approachable & Added smile, removed furrowed brow & V.2 to $\mathrm{V} .3$ \\
\hline Interactivity & $\begin{array}{l}\text { Poor eye contact, low interactivity, limited opportunity } \\
\text { to ask questions or have responses tailored to personal } \\
\text { needs }\end{array}$ & $\begin{array}{l}\text { Focused eye gaze, added randomness in eye move- } \\
\text { ments (e.g., static to dynamic), new response option } \\
\text { for health behavior questions (e.g., "yes, occasionally"), } \\
\text { reduced extra info in VHA script }\end{array}$ & V.2 to $V .3$ \\
\hline Voice & $\begin{array}{l}\text { Reading from a script, too fast/ loud, persuasive intent, } \\
\text { subtitles not synched with audio }\end{array}$ & $\begin{array}{l}\text { Selected race and gender concordant voice, adjusted } \\
\text { subtitle speed, hired professional voice actors to record } \\
\text { script, presented options to users }\end{array}$ & All \\
\hline
\end{tabular}
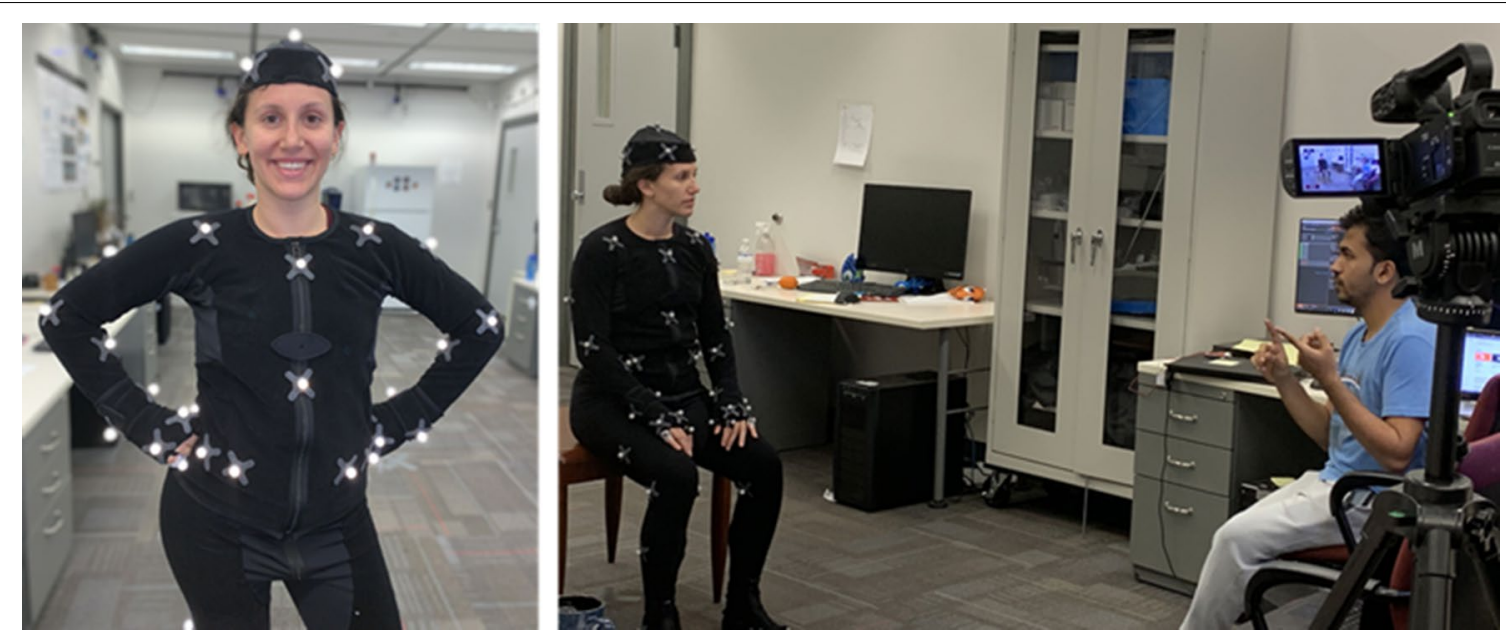

Fig. 1 An actor wears a motion-capture suit as they prepare to read the scripted text of the intervention while their gestures are recorded in a session with research team member and co-author (MZ)

perceptions of the VHA's age improved evaluations of expertise across versions (Fig. 2).

\section{Navigability}

The ease at which users could move through the intervention was important as indicated by one participant whose app unexpectedly paused during use commented, "I was getting a little antsy because this kept dropping, but I stuck with it because I know how important this is." (P113, FG5, VER2). All versions of the app contained a pause button. Versions 2 and 3 were adapted allowing participants to pause the interaction by tapping the 


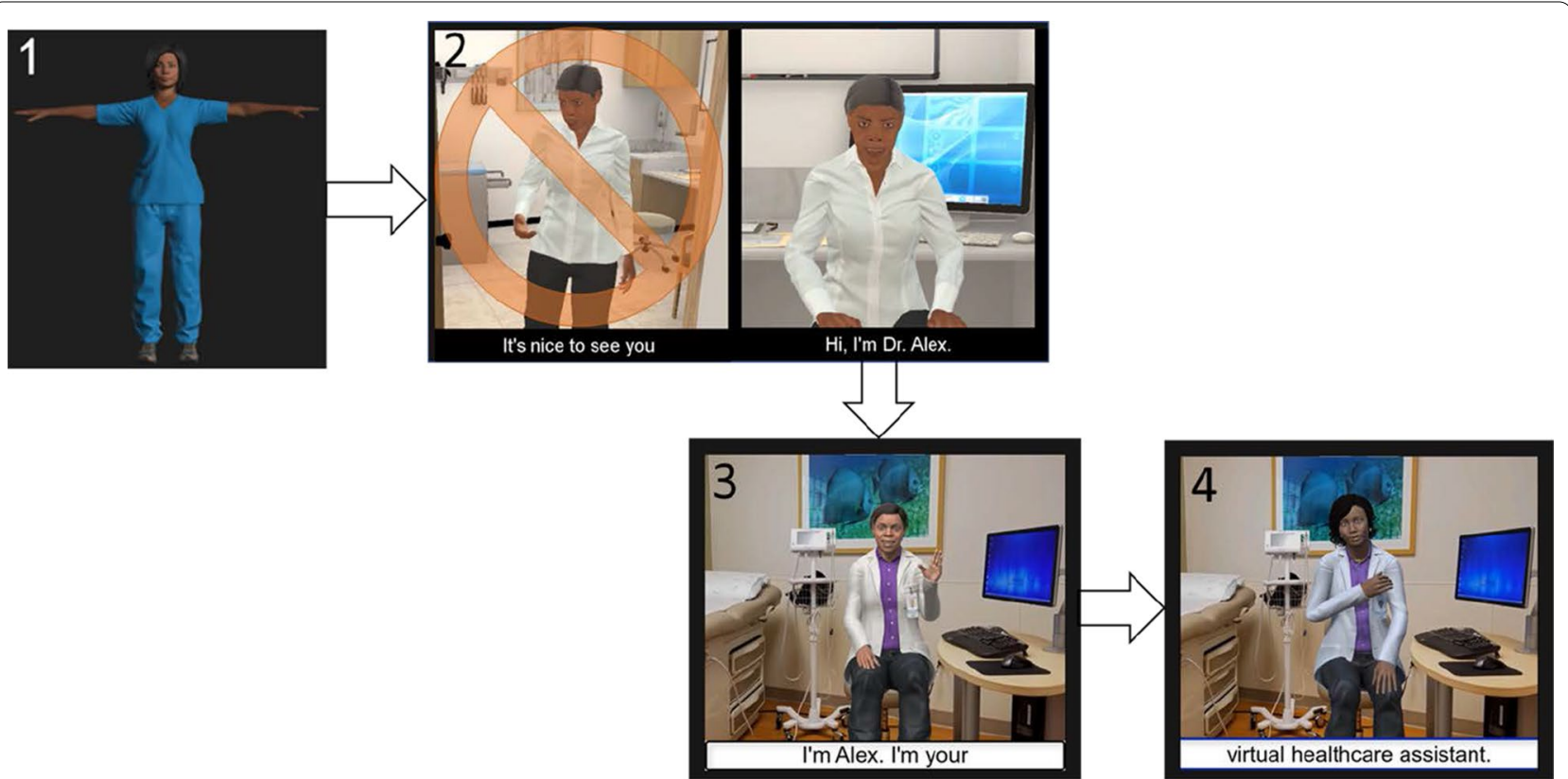

Fig. 2 Overview of design changes. (1) Selected example of print stimulus presented to participants on printed sheets of paper in early data collection sessions. (2) Screen shots from the animated and interactive versions of the virtual health assistant (VHA) delivering colorectal cancer screening messages. These interactive versions were tested on mobile phones. Images show design changes across the three interactive versions. Interactive version 1 eliminated an introduction showing a closed door and the VHA opening to greet user, then walking back to her chair (image 2). Interactive versions 2 and 3 (images 3 and 4) show updates to the clinic room environment, attire, and appearance among other updates detailed in Table 3

mobile phone screen and resumed by clicking a play button. Although indicated as a preference, no version contained a rewind or fast-forward option, as these were hypothesized to interfere with validity during future testing in the clinical trial phase. Audio narration was subtitled throughout, however versions 2 and 3 featured larger subtitle text size. A chat log was eliminated after version 1 , as participants did not find it useful. Additionally, a waiting room scene was removed based on feedback, "if you go straight to the [VHA], I think you would get more people to use it. Don't take them through the step of waiting in a waiting room...because honestly, if I go there and they're like, you're number such and such, you need to sign in... I'm not doing it." (P35, FG3, VER1).

Table 4 Results of non-parametric median test comparing user perceptions by version tested

\begin{tabular}{|c|c|c|c|c|c|c|}
\hline \multirow[t]{2}{*}{ Parameter } & \multicolumn{3}{|c|}{ Median (Q1, Q2) } & \multicolumn{2}{|c|}{ Statistics } & \multirow[t]{2}{*}{$\mathrm{N}$} \\
\hline & Version 1 & Version 2 & Version 3 & $\mathrm{H}(\mathrm{a})$ & $P$ value & \\
\hline The virtual human looked like a doctor & $2(2,4)$ & $2.5(1.3,4)$ & $2(2,2.5)$ & 2.057 & 0.358 & 39 \\
\hline There was too much inconsistency in this application & $4(4,4)$ & $4(1.75,4)$ & $4(4,5)$ & 4.150 & 0.126 & 39 \\
\hline The application was easy to use & $2(1,2)$ & $1.5(1,2)$ & $2(1,2)$ & 1.660 & 0.435 & 39 \\
\hline The virtual human looked very realistic & $2(2,4)$ & $3(2,4)$ & $2(2,3)$ & 0.503 & 0.778 & 33 \\
\hline The virtual human had a pleasing voice & $2(2,2)$ & $2(2,2)$ & $2(1,2)$ & 3.097 & 0.213 & 32 \\
\hline $\begin{array}{l}\text { The virtual human's gestures distracted me as I tried to listen } \\
\text { (reverse scored) }\end{array}$ & $2(1,2)$ & $3.5(2,4)$ & $2(1.5,2)$ & 12.102 & $0.002^{*}$ & 40 \\
\hline The virtual human's gestures distracted me as I tried to listen & $4(4,5)$ & $2.5(2,4)$ & $4(4,4.5)$ & 0.623 & 0.732 & 40 \\
\hline The virtual human looked trustworthy & $2(2,3)$ & $2(2,3)$ & $2(2,2)$ & 2.665 & 0.264 & 41 \\
\hline The virtual human looked like an expert & $3(2,3)$ & $3(2,3)$ & $2(1.5,2)$ & 6.078 & $0.048^{*}$ & 39 \\
\hline
\end{tabular}

${ }^{*}$ Statistical difference detected between groups $(p<.05)$ with sig. values adjusted by Bonferroni for multiple tests; (a) the test statistic adjusted for ties. $1=$ strongly agree and $5=$ strongly disagree 


\section{Quantitative results: perceptions of VHA and application}

Analysis of questionnaire items representing relevant domains of change, revealed two statistically significant items (Table 4). An independent-samples median test indicated responses to "The virtual humans gestures distracted me as I tried to listen" were significantly different across the iterations tested, $H(2) 12.102, p=0.002$. Posthoc analysis with a Bonferroni correction for multiple tests indicate, version 2 was significantly more distracting than version $3(p=0.002)$. Version 1 was not significantly different from Version $2(p=0.144)$ or Version 3 $(p=0.648)$. This difference was only found for the reverse scored question. Additionally, responses to "The virtual human looked like an expert" were significantly different across iterations, $H(2) 6.078, p=0.048$. Post-hoc analysis revealed that version 3 was perceived as more expert than version $2(p=0.023)$. However, when adjusted for multiple tests with the Bonferroni correction, differences between version 2 and 3 were no longer significant $(p=0.068)$. No other items were significantly different.

\section{Discussion}

VHAs were adapted to mimic desired social and physical cues associated with acceptability. The UCD process allows for team and user feedback, in a timely workflow. This allows for quick and systematic development of the technology. A number of changes that influenced acceptance and useability of a VHA-delivered screening intervention among Black women are discussed. Cues related to social presence, trustworthiness, expertise, and navigability were important. Participant description of these cues informed changes to sequential iterations of the intervention. While this paper focuses on the specific topic of colorectal cancer screening, the process of systematically and iteratively engaging community members in design decisions for web-based interventions can be applied to many health-promotion goals and topics. Using adaptive technology-based intervention design strategies has promoted sustained participant engagement various populations [32].

Exploratory analysis of questionnaire data revealed significant differences in perceptions of some cues across the 3 versions tested, which correspond with the timeline of key changes based on participant feedback. For example, changes made to improve perceptions of VHA movements (e.g., I was distracted by the VHAs gestures) between version 2 and 3, were confirmed successful with statistically significant differences (improvement) found between version 2 and 3 on Questionnaire data.

Consistent with the literature [33-36], our results confirm STAM and the UCD process are effective ways to ensure patient expectations are met (e.g., attaining the right level of relevant cues) in an efficient timeframe. This is an important consideration as the role of technology in health promotion continues to expand. In fact, new definitions of health literacy include expectations that organizations assume responsibility for ensuring materials are easy to use, in contrast to previous definitions of it as an individual characteristic [37]. Reframing health literacy from individual deficit to organizational responsibility is well aligned with a UCD approach. For one, a UCD takes responsibility for engaging individuals in the process of creating effective and usable health materials. Thus, a deficit model of individual failure is less likely to be applied to individuals who do not meaningfully engage with content.

\section{Social presence}

Previous work demonstrates when unfamiliar with a platform (e.g. mobile application or website) people rely more on traditional cues and less on information requiring experience with the platform [38]. Humanlike qualities can help virtual agents seem more familiar. Comments suggesting the VHA was fake and/or scary indicated that early versions of the VHA may have had insufficient social presence. However, when users perceived the VHA as a computer with additional access to information, a perceived benefit of the VHA was it could provide reliable, unbiased information more efficiently than a human. The VHA being "not fully human" may create a sense of trust and freedom to circumnavigate inherent biases and racism that can shape communication of health information for Black and minoritized populations. Additionally, apprehension about collecting stool and the invasive colonoscopy modality are documented factors that lead to poor screening. The VHA may have also contributed to enhanced engagement as a trusted source of information who could provide visual demonstrations of stool collection to actively address barriers.

\section{Trustworthiness}

Trust is an essential component of health communication that has special considerations when technology is used. Questionnaire data indicated that overall, all versions were considered trustworthy. Qualitative data provide additional insights on trust. Specifically, patients felt positive about not being targeted by the VHA. Previous research confirms feeling categorized based on risk factors can produce a sense of hopelessness, especially when risk factors are non-modifiable (e.g., age, race, genetic factors) [39, 40]. These findings suggest the VHA avoided making women feel labeled as a risky population. That a culturally-tailored VHA does not make Black women feel targeted has important implications for health disparities work. Virtual agents provide an opportunity to explore and redefine trust. In this case, being perceived as friendly, with a kind voice, and 
overall appearance helped women engage the technology and messages being delivered.

\section{Expertise and authority}

Preferences for authority, clothing and age played an important role in women's assessments of expertise. Acceptable calibration of these cues required many tries. For example, researchers first thought patients would respond positively to a community health worker, and dressed the VHA in casual clothing, which was unacceptable. Scrubs were also less preferred compared to a VHA wearing a white medical coat. These findings provide an opportunity to assess how cues that confer expertise can be extended and communicated virtually. There is also an opportunity to assess how different cues confer authority on the VHA compared to cues that signal authority with real-life health providers.

\section{Navigability}

When expectations about functionality, features, and movement through a technology are not met it can negatively affect acceptability judgments, and perceived usefulness. Subtitles, lack of a back button, ability to select multiple responses to questions, and presences of a clickable pause button all affected ease of use perceptions. Participants' discussions revealed that these cues worked together to shape perceptions. Expectancy violations, typo's in written sources, poor site design, poor visual appearance, and nonprofessional looking content can result in low acceptability. For our audience, details such as the size of subtitled text, synchronicity of movements with audio, were relevant features of this technology. Web-based interventions should be studied to enhance engagement and acceptability among an diverse older adults, to eliminate the potential of a digital divide among populations who can reap a number of benefits from novel health technologies.

\section{Limitations}

While there was interest in customizing the app (e.g., real-time selection and individual tailoring of specific features), participants were not able to select their agent prior to the interaction. Other limitations include inability to assess perceptions of non-concordant VHAs. Additionally, participants who tested print prototypes were not included in exploratory statistical analysis. Finally, some cues (e.g., friendliness, clothing) were not explicitly asked on questionnaires and could not be triangulated with qualitative insights.

\section{Conclusions}

This systematic assessment of adaptations to a VHA and features of web-based intervention promoting cancer screening defines acceptable cues based on Black women's perceptions. Modifiable, non-verbal behaviors such as facial expressions, gaze, and gestures can improve acceptability, as can graphics, text subtitles, and audio content. For an ageing, minoritized population, previous experiences with medical care may affect perceptions of cues and overall acceptability of the technology. Remaining questions include what combination of cues trigger optimal engagement? The rapid expansion of health technologies provides opportunities to document key strategies for creating engaging, easy to use, and acceptable tools for rural, ageing, and minoritized populations.

\section{Acknowledgements \\ Thanks to the participants in all phases of the study as well as community advisory board members who inform various aspects of the larger research study of which this article is part of.}

\section{Authors' contributions}

All authors have made substantial contributions to the conception, design, or acquisition, analysis, interpretations of the data as well as drafting or critically revising the work. All authors agree to the final submitted version and agree to be accountable for all aspects of the work. All authors read and approved the final manuscript.

\section{Funding}

This research was supported by the National Cancer Institute, National Institutes of Health, Award \#R01CA207689. The content is solely the responsibility of the authors and does not necessarily represent official views of the NIH.

\section{Availability of data and materials}

The datasets supporting the conclusions of this article are available upon reasonable request. Contact Janice L. Krieger, janicekrieger@ufl.edu for data requests.

\section{Declarations}

\section{Ethics approval and consent to participate}

The proposal for this study was reviewed by the Safety Review Monitoring Committee (SRMC) and the Institutional Review Board (IRB) at the University of Florida. All participants provided informed written consent to participant in the study.

\section{Consent for publication}

Written informed consent was collected from all study participants. Written consent to publish identifying images of the research team members pictured in Figure 1 was also collected.

\section{Competing interests}

The authors declare that they have no competing interests.

\section{Author details}

${ }^{1}$ STEM Translational Communication Center (STCC), University of Florida, Weimer Hall 2043, PO Box 118400, Gainesville, FL 32611, USA. ²Bethune-Cookman University, Daytona Beach, USA. ${ }^{3}$ Computer and Information Science and Engineering, University of Florida, Gainesville, USA. ${ }^{4}$ Health Outcomes and Biomedical Informatics, University of Florida, Gainesville, USA. ${ }^{5}$ Hematology and Oncology, University of Florida, Gainesville, USA. ${ }^{6}$ College of Pharmacy and College of Medicine, University of Florida, Gainesville, USA. ${ }^{7}$ Community Health and Family Medicine, University of Florida, Gainesville, USA.

Received: 19 January 2021 Accepted: 27 May 2021

Published online: 22 June 2021 


\section{References}

1. Bagchi AD. Expansion of telehealth across the rural-urban continuum State Local Govern Rev. 2019;51(4):250-8. https://doi.org/10.1177/01603 23X20929053.

2. Levitt AF, Ling SM. COVID-19 in the long-term care setting: the CMS perspective. J Am Geriatr Soc. 2020;68(7):1366-9. https://doi.org/10.1111/ jgs.16562.

3. Atkinson NL, Saperstein SL, Desmond SM, Gold RS, Billing AS, Tian J. Rural eHealth nutrition education for limited-income families: an iterative and user-centered design approach. J Med Internet Res. 2009;11(2):e21. https://doi.org/10.2196/jmir.1148.

4. Pak R, McLaughlin AC. Aging, Technology and Health. Elsevier; 2018. https://doi.org/10.1016/C2015-0-06164-0.

5. Thompson HS, Shelton RC, Mitchell J, Eaton T, Valera P, Katz A. Inclusion of underserved racial and ethnic groups in cancer intervention research using new media: a systematic literature review. J Natl Cancer Inst Monogr. 2013;2013(47):216-23. https://doi.org/10.1093/jncimonographs/ lgt031.

6. Davis FD. Perceived usefulness, perceived ease of use, and user acceptance of information technology. MIS Q Manag Inf Syst. 1989;13(3):319-39. https://doi.org/10.2307/249008

7. Chen K, Chan AHS. Gerontechnology acceptance by elderly Hong Kong Chinese: a senior technology acceptance model (STAM). Ergonomics. 2014;57(5):635-52. https://doi.org/10.1080/00140139.2014.895855.

8. Anderson K, Burford O, Emmerton L. Mobile health apps to facilitate selfcare: a qualitative study of user experiences. PLOS ONE. 2016. https://doi. org/10.1371/journal.pone.0156164.

9. American Cancer Society. Cancer Facts and Figures 2019. 2019. https:// www.cancer.org/content/dam/cancer-org/research/cancer-facts-andstatistics/annual-cancer-facts-and-figures/2019/cancer-facts-and-figur es-2019.pdf Accessed 24 Sept 2019.

10. May FP, Glenn BA, Crespi CM, Ponce N, Spiegel BMR, Bastani R. Decreasing black-white disparities in colorectal cancer incidence and stage at presentation in the United States. Cancer Epidemiol Biomark Prev. 2017;26(5):762-8. https://doi.org/10.1158/1055-9965.EPI-16-0834.

11. Cole AM, Jackson JE, Doescher M. Colorectal cancer screening disparities for rural minorities in the United States. J Prim Care Community Health. 2013:4(2):106-11. https://doi.org/10.1177/2150131912463244.

12. Blake KD, Moss JL, Gaysynsky A, Srinivasan S, Croyle RT. Making the case for investment in rural cancer control: an analysis of rural cancer incidence, mortality, and funding trends. Cancer Epidemiol Biomark Prev. 2017:26(7):992-7. https://doi.org/10.1158/1055-9965.EPI-17-0092.

13. Gupta S, Halm EA, Rockey DC, et al. Comparative effectiveness of fecal immunochemical test outreach, colonoscopy outreach, and usual care for boosting colorectal cancer screening among the underserved a randomized clinical trial supplemental content at jamainternalmedicine.com original investigation. JAMA Intern Med. 2013;173(18):1725-32. https:// doi.org/10.1001/jamainternmed.2013.9294.

14. Zhou S, Bickmore T, Paasche-Orlow M, Jack B. Agent-user concordance and satisfaction with a virtual hospital discharge nurse. In: Bickmore T, Marsella S, Sidner C, editors. Lecture notes in computer science (including subseries lecture notes in artificial intelligence and lecture notes in bioinformatics) LNAl, vol. 8637. Berlin; 2014. p. 528-41.

15. Lucas GM, Gratch J, King A, Morency L-P. It's only a computer: virtual humans increase willingness to disclose. Comput Hum Behav. 2014;37:94-100. https://doi.org/10.1016/J.CHB.2014.04.043.

16. Koo JH, Leong RWL, Ching J, et al. Knowledge of, attitudes toward, and barriers to participation of colorectal cancer screening tests in the AsiaPacific region: a multicenter study. Gastrointest Endosc. 2012;76(1):12635. https://doi.org/10.1016/j.gie.2012.03.168.

17. Beydoun HA, Beydoun MA. Predictors of colorectal cancer screening behaviors among average-risk older adults in the United States. Cancer Causes Control. 2008;19(4):339-59. https://doi.org/10.1007/ s10552-007-9100-y.

18. Griffith KA, McGuire DB, Royak-Schaler R, Plowden KO, Steinberger EK. Influence of family history and preventive health behaviors on colorectal cancer screening in African Americans. Cancer. 2008;113(2):276-85. https://doi.org/10.1002/cncr.23550.

19. Office of Disease Prevention and Health Promotion, U.S. Department of Health and Human Services. Health Communication and Health Information Technology Workgroup. Healthy People 2030.
20. Biocca F, Harms C, Burgoon JK. Toward a more robust theory and measure of social presence: review and suggested criteria. Presence Teleoperators and Virtual Environ. 2003;12(5):456-80. https://doi.org/10.1162/10547 4603322761270.

21. Biocca F, Burgoon JK, Stoner GM. Criteria and scope conditions for a theory and measure of social presence see profile. 2001. https://www. researchgate.net/publication/239665882. Accessed 30 Sept 2020

22. Short J, Williams E, Christie B. The social psychology of telecommunications. Wiley; 1976.

23. Burgoon JK, Hale JL. Validation and measurement of the fundamental themes of relational communication. Commun Monogr. 1987:54(1):1941. https://doi.org/10.1080/03637758709390214.

24. Loth S, Gratch J, Nitsch V, et al. Comprehension and engagement in survey interviews with virtual agents. Front Psychol. 2015;6:1578. https:// doi.org/10.3389/fpsyg.2015.01578.

25. Chuah $\mathrm{JH}$, Robb A, White $\mathrm{C}$, et al. Exploring agent physicality and social presence for medical team training. Presence Teleoperators Virtual Environ. 2013;22(2):141-70. https://doi.org/10.1162/PRES_a_00145.

26. Zalake $M$, Tavassoli F, Duke K, et al. Internet-based tailored virtual human health intervention to promote colorectal cancer screening: design guidelines from two user studies. J Multimodal User Interfaces. 2021;15:1-16. https://doi.org/10.1007/s12193-020-00357-5.

27. Vilaro MJ, Wilson-Howard DS, Griffin LN, Tavassoli F, Zalake MS, Lok BC, Modave FP, George TJ, Carek PJ, Krieger JL. Tailoring virtual human-delivered interventions: A digital intervention promoting colorectal cancer screening for Black women. Psycho-Oncology. 2020;29(12):2048-56. https://doi.org/10.1002/pon.5538.

28. Krieger JL, Neil JM, Duke KA, et al. A pilot study examining the efficacy of delivering colorectal cancer screening messages via virtual health assistants. Am J Prev Med. 2021. https://doi.org/10.1016/j.amepre.2021. 01.014

29. Qualtrics. 2005. Provo, Utah, USA. Available at: https://www.qualtrics.com.

30. Czaja SJ, Boot WR, Charness N, Rogers WA. Designing for older adults. 3rd ed. CRC Press; 2019. https://doi.org/10.1201/b22189.

31. IBM SPSS Statistics for Windows. 2020.

32. Lin P-H, Intille S, Bennett $\mathrm{G}$, et al. Adaptive intervention design in mobile health: intervention design and development in the cell phone intervention for you trial. Clin Trials. 2015;12(6):634-45. https://doi.org/10.1177/ 1740774515597222

33. Czaja SJ, Charness N, Fisk AD, et al. Factors predicting the use of technology: findings from the Center for Research and Education on Aging and Technology Enhancement (CREATE). Psychol Aging. 2006;21(2):333-52. https://doi.org/10.1037/0882-7974.21.2.333.

34. Lee CC, Czaja SJ, Moxley JH, et al. Attitudes toward computers across adulthood from 1994 to 2013. Gerontologist. 2019;59(1):22-3. https://doi. org/10.1093/geront/gny081.

35. Mitzner TL, Savla J, Boot WR, et al. Technology adoption by older adults: findings from the PRISM trial. Gerontologist. 2019;59(1):34-44. https://doi. org/10.1093/geront/gny113.

36. lancu I, lancu B. Designing mobile technology for elderly. A theoretical overview. Technol Forecast Soc Change. 2020;155:119977. https://doi. org/10.1016/j.techfore.2020.119977.

37. Office of Disease Prevention and Health Promotion. History of health literacy definitions. Healthy people 2030.

38. van der Heide B, Lim Y-S. On the conditional cueing of credibility heuristics: the case of online influence. Commun Res. 2016;43(5):672-93. https://doi.org/10.1177/0093650214565915.

39. Hocevar KP, Metzger M, Flanagin AJ, Hocevar KP, Metzger M, Flanagin AJ. Source credibility, expertise, and trust in health and risk messaging. Oxf Res Encycl Commun. 2017. https://doi.org/10.1093/acrefore/9780190228 613.013.287.

40. Peretti-Watel P, Fressard L, Bocquier A, Verger P. Perceptions of cancer risk factors and socioeconomic status. A French study. Prev Med Rep. 2016;3:171-6. https://doi.org/10.1016/j.pmedr.2016.01.008.

\section{Publisher's Note}

Springer Nature remains neutral with regard to jurisdictional claims in published maps and institutional affiliations. 